\title{
Oleic Acid and Cholinergic dysfunction in Down Syndrome Models of the Central Nervous System
}

\author{
Ana Velasco* and Maruan Hijazi
}

Departamento de Bioquímica y Biología Molecular: Instituto de Neurociencias de Castilla y León (INCYL): Universidad de Salamanca: Instituto de Investigación Biomédica de Salamanca (IBSAL): Spain

\section{Article Info}

\section{Article Notes}

Received: May 09, 2016

Accepted: June 02, 2016

\section{*Correspondence:}

Dr. Ana Velasco

Instituto de Neurociencias de Castilla y León (INCYL)

C/ Pintor Fernando Gallego 1: 37007 Salamanca: Spain

Telephone: 34-923294500 Ext 5337

Fax.: 34-923-294564

Email: anvecri@usal.es

(C) 2016 Velasco A. This article is distributed under the terms of the Creative Commons Attribution 4.0 International License

\begin{abstract}
Down syndrome (DS): or trisomy 21: is the most common autosomal aneuploidy and the leading genetic cause of intellectual disability. It is widely established that mental retardation is primarily a consequence of brain functioning and developmental abnormalities in neurogenesis. Some changes in the physical structure of the dendrites are a major cause of impaired synaptic plasticity of DS. The overexpression of the dual specificyty tyrsone phosphorylationregulated kinase 1A (DYRK1A): located on chromosome 21: is involved in cellular plasticity and responsible for central nervous system disturbance in DS.

Oleic acid is a neurotrophic factor that promotes neuronal differentiation and increases the levels of choline acetyltransferase (ChAT). Furthermore: it has recently been shown that it induces migration and formation of new synapses in euploid cells. However: remarkably oleic acid fails to reproduce the same effects in trisomic cells.
\end{abstract}

Here we review the hypothesis that oleic acid-dependent synaptic plasticity may be dependent on the lipid environment. Thus: differences in membrane composition may be essential to understand why oleic acid promotes higher cell plasticity in euploid than in trisomic cells. 


\section{Introduction}

Down syndrome (DS) is characterized by the presence of an extra copy of human chromosome 21 (HSA21). DS is the most frequent genetic form of intellectual disability affecting key brain regions involved in learning and memory processes. These neurological alterations could be the origin of the observed intellectual disability: particularly during development and in adulthood ${ }^{1}$. In this regard: individuals with DS have reduced brain volume: fewer neurons and alterations in the dendritic tree: all of which could partly explain the intellectual disability ${ }^{2}$. Histological brain studies of people with DS showed an abnormal formation of the cerebral cortex : produced in part by a cellular alteration in the cortex layers II and III $^{3}$. Human cortical development appears normal until week 22 of gestation. However: lower lamination and pattern of cortical maturation appears in week 40 and reflects an abnormal dendritic arborization during the first year of life $\mathrm{e}^{3: 4}$. Some authors previously described alterations in neurotransmitter and its receptors as responsible for distinctive phenotypic traits. in $\mathrm{DS}^{5}$.

\section{Oleic acid as a Potential Neurotrophic Factor}

Oleic acid is a fatty acid that acts a neurotrophic factor during postnatal brain development. It is synthesized and released by astrocytes ${ }^{6}$. Physical properties of oleic acid are determined by the position of the double bond in the chain. Oleic acid has profound effects on membrane fluidity since phospholipids containing acyl chains of oleic acid increase membrane fluidity ${ }^{7}$. Membrane fluidity is critical for neurons and the incorporation of oleic acid-borne phospholipids into a discrete area of the membrane could substantially change membrane properties. In agreement with this: oleic acid is preferentially incorporated into neurite bases $^{8}$ : suggesting that increased fluidity is required at the sites of newly emerging axons and/or dendrites. This would facilitate the sprouting of the membrane during neurite growth together with enhanced flexibility for axon orientation ${ }^{9}$.

In addition: oleic acid increases in the brain of rat fetuses between 15 and 17 days of gestation ${ }^{10}$ : overlapping with the maximum expansion of rat brain development. In fact: it is precisely during this period that a delay in the formation of the cortex in trisomic mice TS16 occurs ${ }^{11}$ [11]: possibly due to an alteration in neurogenesis: migration and cell differentiation ${ }^{12: 13}$.

\section{DYRK1A in Down Syndrome}

Dyrk1A is a dual specificity protein kinase that is regulated by autophosphorylation on Ser: Thr and Tyr residues and also capable of phosphorylating proteins at both Ser/Thr residues. Deregulation of Dyrk1A expression produces a wide variety of phenotypic alterations during development and even in adult stages $^{14-16}$. This is due to its involvement in multiple signaling pathways that makes DYRK1A a key player in the regulation of different biological processes. Dyrk1A is overexpressed in DS brains and is involved in neurogenesis and learning/memory ${ }^{17}$. Transgenic mice overexpressing DYRK1A (TgDyrk1A) exhibit DSlike features such as neurodevelopmental delay: motor abnormalities and cognitive deficits ${ }^{14}$.

\section{Highlighting the Potencial Role for Oleic Acid in the Cholinergic System}

Trisomic cell lines are useful tools to study DS. Cell lines from the cerebral cortex of wild-type mouse fetuses (CNh) and trisomic TS16 (CTb) are widely used in the literature. These cell lines were developed at the laboratory of Dr. Pablo Caviedes (University of Chile: contact: pcaviede@ med.uchile.cl) and are marketed through an agreement with the University of South Florida). CNh and CTb cells retain neuronal markers such as neuronal specific enolase (NSE): choline acetyltransferase (ChAT): synaptophysin: microtubule-associated protein 2 (MAP2) and a lack of the glial markers (GFAP: galactocerebroside: S-100) ${ }^{18}$. CTb cells overexpress DS-related genes (Dyrk1A: App: Sod1: $\mathrm{Cu} / \mathrm{Zn}$ superoxide dismutase) and show altered cholinergic function: involving reduced choline uptake and ChAT expression: together with a fractional acetylcholine release after stimulation ${ }^{19}$.

By using these cell lines: we previously showed that trisomic cells do not respond to the presence of oleic acid as euploid cells. Unlike trisomic cells: euploid cells tend to aggregate in response to oleic acid in a similar way as neurons in primary culture ${ }^{20}$. These results suggest that trisomic cells may have an alteration in oleic acid signal transduction $^{21: 22}$. In the characterization of CTb cells: Allen et $a .^{23}$ reported that these cells show similar cholinergic deficits to those presented in murine Ts16: an animal model for Down syndrome. These alterations involve reduced activities of ChAT and acetylcholinesterase (AChE) ${ }^{24: 25}$ : which is accompanied by a reduced synthesis of the neurotransmitter acetylcholine and a less choline uptake into the brain ${ }^{26}$. To study the role of oleic acid in cholinergic system: we analized ChAT expression in euploid and trisomic cells. Our results indicated that oleic acid induced the expression of ChAT in euploid cells: but not in trisomic cells $^{20}$. In agreement with this: neurochemical dissection of synaptic pathology in the cerebral cortex of patients with DS showed a significant reduction of the activity of ChAT $^{27}$ : suggesting the existence of abnormalities in the cholinergic system in DS models and changes in electrical properties of cell membranes ${ }^{23}$. Some authors suggest that basal forebrain cholinergic system is apparently normal in fetuses and newborns with DS since the number of neurons and ChAT activity remain unaltered ${ }^{28: 29}$. Our recent data 
confirm that there are not differences in the number of neurons expressing ChAT between euploid and trisomic cells: although a decrease was observed in the intensity of ChAT expression in trisomic cells compared to euploid cells $^{20}$. These results suggest that the presence of oleic acid increases ChAT expression: confirming previous results which highlighted the role of oleic acid in the cholinergic system $^{30}$.

\section{DYRK1A overexpression Inhibits the Effect of Oleic Acid in Down Syndrome}

In order to study the possible connection between overexpression of Dyrk1A and disregulation of the oleic acid-promoted ChAT activity: we analysed the effects of oleic acid in ChAT expression after downregulating DYRK1A by siRNA in CNh and CTb cells. We found that the downregulation of DYRK1A in CTb cells rescued the phenotype of normal cells. Moreover: ChAT expression increased in DYRK1A-silenced trisomic cells up to the same levels found in normal cells. These results suggested that the overexpression of DYRK1A prevented the induction of ChAT promoted by oleic acid in CTb cells ${ }^{20}$.

To further evaluate the potential involvement of DYRK1A in the regulation of ChAT expression promoted by oleic acid: we analysed ChAT levels in primary neuronal cultures from transgenic mice overexpressing DYRK1A (TgDyrk1A). TgDyrk1A mice were previously generated at the laboratory of Dr. Cristina Fillat and exhibit DS-like features: such as neurodevelopmental delay: motor abnormalities and cognitive deficits: as described in Altafaj et al. ${ }^{14}$. Immunocytochemical and western blot analysis revealed an increase in ChAT expression in wild-type neurons caused by oleic acid. These results were in agreement with previous data showing an increase in ChAT expression due to the presence of fatty acids ${ }^{31: 32}$. However: we did not observe an increase in ChAT expression in neuronal cultures from transgenic mice upon treatment with oleic acid. In agreement with this: the presence of oleic acid did not promote profound changes in the shape of the neurons from TgDyrk1A mice: unlike the situation in wild-type cells. Thus: whereas wild-type neurons exposed to oleic acid tended to aggregate to form clusters and elongated axons and dendrites: these morphological changes were not observed in TgDyrk1A neurons: suggesting impairment in neuronal differentiation in TgDyrk1A mice. In agreement with this observation: the expression of GAP-43: a marker of axonal growth: was also increased in the presence of oleic acid in wild-type neurons: while it was almost unaltered in TgDyrk1A cultures. Taken together these results: we hypothesize that the overexpression of Dyrk1A acts a negative regulator of cholinergic differentiation promoted by oleic acid.
Synthesis of Phosphatidylcholine is Restrained in Down Syndrome Cells

Previous studies indicated that monounsaturated fatty acid levels are lower in brains of DS patients ${ }^{33: 34}$ and presumably involve changes in the efficacy of synaptic connections: a phenomenon present in these patients ${ }^{35}$. Phosphatidylcholine (PC) analysis from euploid and trisomic cells show that in the presence of oleic acid a significant increase occurs in the amount of PC in euploid cells: but not in trisomic cells ${ }^{36}$. However: this effect does not occur when cells are incubated with other fatty acids: such as palmitic acid or stearic acid. These results confirm the specificity of oleic acid as neurotrophic factor ${ }^{37}$. Confocal analysis revealed that oleic acid accumulated in the plasma membrane and endoplasmic reticulum in both cell lines. However: an abnormal distribution of oleic acid in trisomic cell membranes was observed: with a markedly disrupted fluorescence intensity along the membrane ${ }^{36}$. Since previous studies have reported that oleic acid is preferentially incorporated into $\mathrm{PC}$ in the neuronal plasma membrane ${ }^{8}$ : these findings are consistent with the significant reduction in monounsaturated fatty acid composition of phospholipids detected in the brains of people with Down's syndrome ${ }^{33}$. The incorporation of oleic acid to membrane phospholipids may alter the biophysical properties of the membrane and thereby regulate the activity of integral or peripheral membrane proteins ${ }^{38}$.

Analysis of phospholipid synthesis in trisomic and euploid cells showed that there was a deficit in phospholipid synthesis in trisomic cells ${ }^{36}$. The expression of enzymes regulating PC synthesis: choline kinase alpha and CTP-choline cytidylyltransferase1 alpha (choline cytidylyltransferase alpha): was decreased: while CDPcholine: 1:2-diacylglycerol choline phosphotransferase were increased in trisomic cells compared to euploid cells ${ }^{36}$. In addition to this pathway: PC can be synthesized through an alternative route that uses phosphatidylethanolamine and S-adenosylmethionine (methyl donor) as precursors and phosphatidylethanolamine methyltransferase (PEMT) and SAHH as catalytic enzymes. Activity of these enzymes is critical to PC synthesis in certain circumstances ${ }^{39}$. We showed that expression analysis of both genes revealed that PEMT levels were upregulated while SAHH levels were significantly downregulated in CTb cells ${ }^{36}$.

\section{Role of Dyrk1A in PC Synthesis in Down Syndrome Cells}

Planque et al. ${ }^{40}$ previously reported that overexpression of Dyrk1A affects the activity of S-adenosylhomocysteine hydrolase: which would prevent the recycling of S-adenosylhomocysteine to S-adenosylmethionine: resulting in a decrease in PC synthesis. However: our data reveals that the expression of those genes involved in 

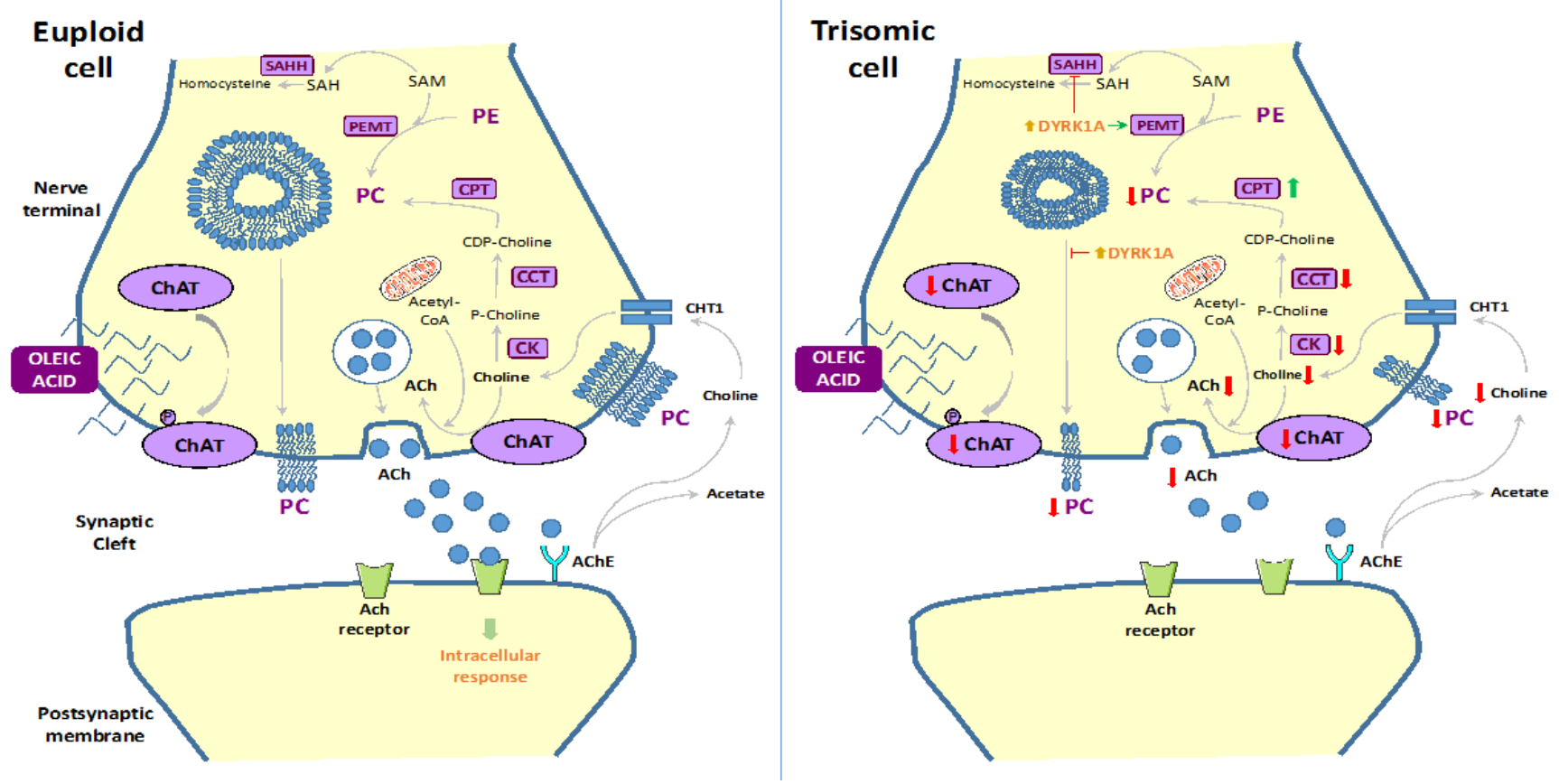

Figure: Proposed model to summarize the cholinergic dysfunction in Down syndrome.

Kennedy pathway is not altered by overdose of Dyrk1A: since downregulation of Dyrk1A by siRNA does not produce any significant change in the expression of choline kinase alpha and CTP-choline cytidylyltransferase 1 alpha. Interestingly: downregualtion of Dyrk1A significantly altered both PEMT and SAHH levels in the opposite way. This result suggests that Dyrk1A may be involved in the regulation of the latter pathway: preventing recycling $\mathrm{SAH}$ to $\mathrm{SAMe}^{40}$ and eventually resulting in the inhibition of PC synthesis. Further studies of genes involved in the conversion of phosphatidylethanolamine in PC will clarify the role of Dyrk1A in the synthesis of PC in trisomic cells.

Taken together: we conclude that a deregulation of PC biosynthetic pathways may occur in trisomic cells: although its relationship with Dyrk1A activity remains to be elucidated. Further experiments will be needed to get inside the relationships between Dyrk1A activity and PC biosynthesis in order to board the treatment of DS with new Dyrk1A inhibitors (Figure 1).

Oleic acid increases PC levels and localizes into the plasma membranes of euploid cells. However: overexpression of Dyrk1A prevents a proper PC incorporation into the plasma membrane of trisomic cells. In addition: murine Ts16 showed a reduction in ChAT expression: a significant decrease in choline uptake by the high-affinity choline transporter: together with a decrease in acetylcholine release.

\section{Abbreviations}

ACh: acetylcholine; AChE: acetylcholinesterase; CHT1: high-affinity choline transporter; PC: phosphatidylcholine; PE: phosphatidylethanolamine; DYRK1A: dual-specificity tyrosine-phosphorylated and regulated kinase-1A; ChAT: choline acetyltransferase; CK: choline kinase; CCT: choline cytitylyltransferase; CPT: CDP-choline:1,2-diacylglycerol phosphocholinetransferase; PEMT: phosphatidylethanolamine methyltransferase; SAM: S-adenosylmethionine; SAH: S-adenosylhomocisteine; SAHH: S-adenosylhomocisteine hydrolase.

\section{References}

1. Rachidi M, Lopes C. Molecular and cellular mechanisms elucidating neurocognitive basis of functional impairments associated with intellectual disability in Down syndrome. Am J Intellect Dev Disabil. 2010; 115(2): 83-112.

2. Dierssen M. Down syndrome: the brain in trisomic mode. Nat Rev Neurosci. 2012; 13(12): 844-58.

3. Golden JA, Hyman BT. Development of the superior temporal neocortex is anomalous in trisomy 21. J Neuropathol Exp Neurol. 1994; 53(5): 513-20.

4. Becker L, Mito T, Takashima S, Onodera K. Growth and development of the brain in Down syndrome. Prog Clin Biol Res. 1991; 373: 133-52.

5. Rueda N, Flórez J, Martínez-Cué C. Mouse models of Down syndrome as a tool to unravel the causes of mental disabilities. Neural Plast. 2012; 2012: 584071.

6. Tabernero A, Velasco A, Granda B, Lavado EM, Medina JM. Transcytosis of albumin in astrocytes activates the sterol regulatory elementbinding protein-1, which promotes the synthesis of the neurotrophic factor oleic acid. J Biol Chem. 2002; 277(6): 4240-6.

7. Alberts B. Molecular Biology of the Cell. 2008.

8. Tabernero A, Lavado EM, Granda B, Velasco A, Medina JM. Neuronal differentiation is triggered by oleic acid synthesized and released by astrocytes. J Neurochem. 2001; 79(3): 606-16. 
9. Polo-Hernández E, De Castro F, García-García AG, Tabernero A, Medina JM. Oleic acid synthesized in the periventricular zone promotes axonogenesis in the striatum during brain development. J Neurochem. 2010; 114(6): 1756-66.

10.García-García AG, Polo-Hernández E, Tabernero A, Medina JM. Alphafetoprotein (AFP) modulates the effect of serum albumin on brain development by restraining the neurotrophic effect of oleic acid. Brain Res. 2015; 1624: 45-58.

11. Haydar TF, Blue ME, Molliver ME, Krueger BK, Yarowsky PJ. Consequences of trisomy 16 for mouse brain development corticogenesis in a model of Down syndrome. J Neurosci. 1996; 16(19): 6175-82.

12.Laffaire J, Rivals I, Dauphinot L, Pasteau F, Wehrle R, Larrat B, et al Gene expression signature of cerebellar hypoplasia in a mouse model of Down syndrome during postnatal development. BMC Genomics. 2009; 10: 138.

13. Roper RJ, Baxter LL, Saran NG, Klinedinst DK, Beachy PA, Reeves RH. Defective cerebellar response to mitogenic Hedgehog signaling in Down [corrected] syndrome mice. Proc Natl Acad Sci U S A. 2006; 103(5): $1452-6$

14.Altafaj X, Dierssen M, Baamonde C, Martí E, Visa J, Guimerà J, et al. Neurodevelopmental delay, motor abnormalities and cognitive deficits in transgenic mice overexpressing Dyrk1A (minibrain), a murine model of Down's syndrome. Hum Mol Genet. 2001; 10(18): 1915-23.

15.Arqué G, Fotaki V, Fernández D, Martínez de Lagrán M, Arbonés ML Dierssen M. Impaired spatial learning strategies and novel object recognition in mice haploinsufficient for the dual specificity tyrosineregulated kinase-1A (Dyrk1A). PLoS One. 2008; 3(7): e2575

16. Cheon MS, Kim SH, Fountoulakis M, Lubec G. Heart type fatty acid binding protein (H-FABP) is decreased in brains of patients with Down syndrome and Alzheimer's disease. J Neural Transm Suppl. 2003(67) 225-34

17. Tejedor FJ, Hammerle B. MNB/DYRK1A as a multiple regulator of neuronal development. FEBS J. 2011; 278(2): 223-35.

18.Saud K, Arriagada C, Cárdenas AM, Shimahara T, Allen DD, Caviedes $\mathrm{R}$, et al. Neuronal dysfunction in Down syndrome: contribution of neuronal models in cell culture. J Physiol Paris. 2006; 99(2-3): 201-10.

19.0pazo P, Saud K, de Saint Pierre M, Cárdenas AM, Allen DD, SeguraAguilar J, et al. Knockdown of amyloid precursor protein normalizes cholinergic function in a cell line derived from the cerebral cortex of a trisomy 16 mouse: An animal model of down syndrome. J Neurosci Res. 2006; 84(6): 1303-10.

20.Hijazi M, Fillat C, Medina JM, Velasco A. Overexpression of DYRK1A inhibits choline acetyltransferase induction by oleic acid in cellular models of Down syndrome. Exp Neurol. 2013; 239: 229-34.

21. Bento-Abreu A, Tabernero A, Medina JM. Peroxisome proliferatoractivated receptor-alpha is required for the neurotrophic effect of oleic acid in neurons. J Neurochem. 2007; 103(3): 871-81.

22. Rodríguez-Rodríguez RA, Tabernero A, Velasco A, Lavado EM, Medina JM. The neurotrophic effect of oleic acid includes dendritic differentiation and the expression of the neuronal basic helix-loophelix transcription factor NeuroD2. J Neurochem. 2004; 88(5): 104151.

23.Allen DD, Martín J, Arriagada C, Cárdenas AM, Rapoport SI, Caviedes $\mathrm{R}$, et al. Impaired cholinergic function in cell lines derived from the cerebral cortex of normal and trisomy 16 mice. Eur J Neurosci. 2000; 12(9): 3259-64.
24.Ozand PT, Hawkins RL, Collins RM Jr, Reed WD, Baab PJ, Oster-Granite ML. Neurochemical changes in murine trisomy 16: delay in cholinergic and catecholaminergic systems. J Neurochem. 1984; 43(2): 401-8.

25.Sweeney JE, Höhmann CF, Oster-Granite ML, Coyle JT. Neurogenesis of the basal forebrain in euploid and trisomy 16 mice: an animal model for developmental disorders in Down syndrome. Neuroscience. 1989; 31(2): 413-25

26. Fiedler JL, Epstein CJ, Rapoport SI, Caviedes R, Caviedes P. Regional alteration of cholinergic function in central neurons of trisomy 16 mouse fetuses, an animal model of human trisomy 21 (Down syndrome). Brain Res. 1994; 658(1-2): 27-32.

27.Yates CM, Simpson J, Gordon A, Maloney AF, Allison Y, Ritchie IM, et al. Catecholamines and cholinergic enzymes in pre-senile and senile Alzheimer-type dementia and Down's syndrome. Brain Res. 1983; 280(1): 119-26.

28. Kish S, Karlinsky H, Becker L, Gilbert J, Rebbetoy M, Chang LJ, et al. Down's syndrome individuals begin life with normal levels of brain cholinergic markers. J Neurochem. 1989; 52(4): 1183-7.

29.Lubec B, Yoo BC, Dierssen M, Balic N, Lubec G. Down syndrome patients start early prenatal life with normal cholinergic, monoaminergic and serotoninergic innervation. J Neural Transm Suppl. 2001; 61: 303-10.

30. Massarelli R, Ferret B, Sorrentino G, Hattori H, Kanfer JN. Choline acetyltransferase-like activity bound to neuronal plasma membranes. Neurochem Res. 1988; 13(12): 1193-8.

31. Hattori H, Kanfer JN, Massarelli R. Stimulation of phospholipase D activity and indication of acetylcholine synthesis by oleate in rat brain synaptosomal preparations. Neurochem Res. 1987; 12(8): 687-92.

32.Machová E, Málková B, Lisá V, Nováková J, Dolezal V. The increase of choline acetyltransferase activity by docosahexaenoic acid in NG10815 cells grown in serum-free medium is independent of its effect on cell growth. Neurochem Res. 2006; 31(10): 1239-46.

33. Murphy EJ, Schapiro MB, Rapoport SI, Shetty HU. Phospholipid composition and levels are altered in Down syndrome brain. Brain Res. 2000; 867(1-2): 9-18.

34.Shah SN. Fatty acid composition of lipids of human brain myelin and synaptosomes: changes in phenylketonuria and Down's syndrome. Int J Biochem. 1979; 10(6): 477-82.

35.Elul R, Hanley J, Simmons JQ $3^{\text {rd }}$. Non-Gaussian behavior of the EEG in Down's syndrome suggests decreased neuronal connections. Acta Neurol Scand. 1975; 51(1): p. 21-28.

36. Hijazi M, Medina JM, Velasco A. Restrained Phosphatidylcholine Synthesis in a Cellular Model of Down's Syndrome is Associated with the Overexpression of Dyrk1A. Mol Neurobiol. 2016.

37. Medina JM, Tabernero A. Astrocyte-synthesized oleic acid behaves as a neurotrophic factor for neurons. J Physiol Paris. 2002; 96(3-4): 26571.

38.Lopez S, Bermudez B, Montserrat-de la Paz S, Jaramillo S, Varela LM, Ortega-Gomez A, et al. Membrane composition and dynamics: A target of bioactive virgin olive oil constituents. Biochim Biophys Acta. 2014; 1838(6): 1638-56.

39.Vance DE. Physiological roles of phosphatidylethanolamine N-methyltransferase. Biochim Biophys Acta. 2013; 1831(3): 626-32.

40.Planque C, Dairou J, Noll C, Bui LC, Ripoll C, Guedj F, et al. Mice deficient in cystathionine beta synthase display increased Dyrk1A and SAHH activities in brain. J Mol Neurosci. 2013; 50(1): 1-6. 